\title{
O manejo de inverno e inoculação de sementes influenciam na produtividade e qualidade da silagem de milho sob sistema plantio direto ${ }^{1}$
}

\author{
Patricia Bertoncelli², Thomas Newton Martin², Jéssica Stecca², Evandro Deak ${ }^{2}$, \\ Marlo Adriano Bison Pinto ${ }^{2}$, Alex Schonell ${ }^{2}$ \\ $10.1590 / 0034-737 X 201764050010$
}

\section{RESUMO}

O objetivo deste trabalho foi avaliar o efeito de resíduos culturais, de doses de nitrogênio e da inoculação de sementes com Azospirillum brasilense sobre os componentes de rendimento e de qualidade da silagem de milho, sob sistema plantio direto. O experimento foi conduzido na Universidade Federal de Santa Maria, RS. O delineamento experimental foi de blocos ao acaso, sendo os tratamentos distribuídos em um fatorial com diferentes resíduos culturais de trigo, cevada e aveia preta (cultivares Fundacep Horizonte, Quartzo, Mirante, Campo Real, BRS Cauê, MN 743

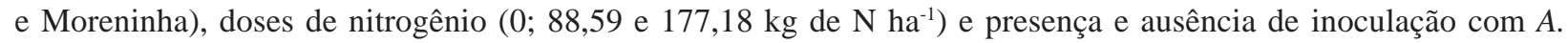
brasilense. Foram avaliados os componentes de produtividade e a qualidade bromatológica do produto ensilado. Os resíduos culturais e as doses de nitrogênio não influenciaram a produtividade de grãos. A silagem do milho cultivado após a cultura da cevada apresentou valores de fibra em detergente neutro inferiores ao milho cultivado após as culturas do trigo e da aveia preta. A aplicação de $177,18 \mathrm{~kg}$ de N ha ${ }^{-1}$ incrementou em pelo menos 2,13 e 2,18 $\mathrm{Mg} \mathrm{ha}^{-1} \mathrm{a}$ massa seca de silagem do milho cultivado, respectivamente, após a cultura da cevada e da aveia preta. A cobertura do solo com a cultura da aveia (cultivar moreninha) no inverno melhora a qualidade bromatológica da silagem de milho. A inoculação com A. brasilense incrementa a produtividade de grãos, porém, não influencia o teor de proteína da silagem do milho.

Palavras-chave: Azospirillum brasilense; adubação nitrogenada; cobertura do solo; Zea mays L.

\section{ABSTRACT}

\section{Winter management and seed inoculation influence the productivity and quality of corn silage ${ }^{1}$}

The purpose of this study was to assess crop residue effects, nitrogen doses, and inoculation of seeds with Azospirillum brasilense concerning yield and corn silage quality using direct planting system. The experiment was carried out at the Federal University of Santa Maria - RS, Brazil. A randomized block design approach was used and treatments were distributed in a factor analysis with different crop residues (cultivars Fundacep Horizonte, Quartzo,

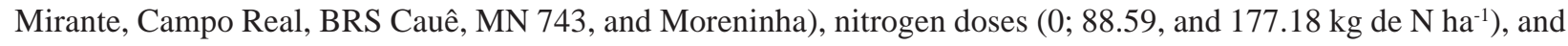
presence and absence of inoculation with $A$. brasilense. Productivity and bromatological quality of the silage product were assessed. Crop residues and nitrogen doses did not influence grain productivity. After barley crop, corn silage presented lower neutral detergent fiber values in relation to maize grown after wheat and black oat crops. The dose of $177.18 \mathrm{~kg} \mathrm{~N} \mathrm{ha}^{-1}$ increased silage dry mass of corn at least by 2.13 and $2.18 \mathrm{Mg} \mathrm{ha}^{-1}$, respectively, after barley and black

\footnotetext{
Submetido em 30/03/2017 e aprovado em 02/10/2017.

' Parte da dissertação de mestrado da primeira autora.

${ }^{2}$ Universidade Federal de Santa Maria, Departamento de Agronomia, Santa Maria, Rio Grande do Sul, Brasil.pb.zootecnia@hotmail.com; martin.ufsm@gmail.com; jeka_stecca@yahoo.com.br; evandro.deak@gmail.com; marlo.bison@gmail.com; alex_ts@hotmail.com

*Autor para correspondência: martin.ufsm@gmail.com
} 
oat crops. The soil cover with an oat crop (cv. Moreninha) in winter improves the bromatological quality of corn silage. Inoculation with $A$. brasilense increases grain yield, but does not influence the protein content of corn silage.

Key words: Azospirillum brasilense; nitrogen fertilization; ground cover; Zea mays L.

\section{INTRODUÇÃO}

Sob sistema plantio direto, o manejo da fertilização nitrogenada torna-se ainda mais abrangente (Albuquerque et al., 2013). As doses e a fonte de nitrogênio são definidas de acordo com o sistema de cultivo e não somente em função da necessidade da cultura a ser semeada (Pires et al., 2011). Em gramíneas, a principal bactéria fixadora de nitrogênio é a Azospirillum brasilense. Esse procarioto fixa nitrogênio atmosférico por meio da enzima nitrogenase, transformando-o em nitrogênio inorgânico $\left(\mathrm{NH}_{3} \mathrm{e}\right.$ ou, $\mathrm{NH}_{4}^{+}$) para que a planta possa absorvê-lo (Taiz \& Zeiger, 2013). Quando comparada com a adubação mineral, a utilização da $A$. brasilense tem a vantagem de não ocorrerem perdas do $\mathrm{N}$ fixado, como ocorre com os fertilizantes minerais (Soares, 2009).

Outras vantagens da utilização de bactérias $A$. brasilense são as possíveis alterações provocadas na morfologia do sistema radicular da planta inoculada. A produção de auxinas pelas bactérias causa o aumento do número de radicelas e raízes laterais, aumentando a superfície de absorção de água e nutrientes (Mumbach $e t$ al., 2017; Sangoi et al., 2015; Müller et al., 2016; Morais et al., 2016; Milléo \& Cristófoli, 2016). Isto torna mais expressiva a capacidade das plantas inoculadas de resistir a estresses causados pelo ambiente (Salomone \& Döbereiner, 1996).

São várias as evidências de que a inoculação das sementes de milho com bactérias da espécie $A$. brasilense seja responsável pelo incremento do acúmulo de matéria seca, o que parece estar relacionado com o aumento da atividade das enzimas fotossintéticas e de assimilação de nitrogênio (Hungria, 2011; Kappes et al., 2013). Existe uma ligação direta entre a formação de grãos e a translocação de metabólitos na planta de milho. Assim, a fixação biológica do nitrogênio pode influenciar tanto a produtividade de grãos, como o valor nutricional da silagem produzida (Martin et al., 2011).

Contudo, as contribuições dessa bactéria para a produção de milho têm mostrado resultados contraditórios (Bartchechen et al., 2010; Hungria, 2011; Godoy et al., 2011; Müller et al., 2016). Dentre os resultados mais promissores devidos à inoculação das sementes com $A$. brasilense, Müller et al. (2016) observaram incremento da ordem de $567 \mathrm{~kg} \mathrm{ha}^{-1}$ da produtividade de grãos, em comparação com a produtividade na ausência da bactéria. $\mathrm{Da}$ mesma forma, Hungria (2011) encontraram aumento de 30\% da produtividade, em comparação com a obtida pelo controle, sem inoculação. Por outro lado, Godoy et al. (2011) utilizaram inoculante com $A$. brasilense em milho e não encontraram respostas da inoculação sobre a produtividade da cultura.

A partir dessas considerações, verifica-se a necessidade de mais informações acerca dos efeitos da interação milho (Zea mays) - A. brasilense. O objetivo deste trabalho foi avaliar o efeito de resíduos culturais, de doses de nitrogênio e da inoculação de sementes com A. brasilense sobre os componentes de rendimento e de qualidade da silagem de milho, sob sistema plantio direto.

\section{MATERIAL E MÉTODOS}

O experimento foi conduzido na área experimental do Departamento de Fitotecnia da Universidade Federal de Santa Maria, situada a $29^{\circ} 43^{\prime} 04^{\prime \prime} \mathrm{S}$ e $53^{\circ} 44^{\prime} 01^{\prime \prime} \mathrm{O}$, em altitude média de 116 metros. O solo da área é um Argissolo Vermelho distrófico arênico (Embrapa, 2013), com topografia plana, e o clima é subtropical úmido, tipo Cfa, segundo classificação de Köppen-Geiger (Peel et al., 2007; Heldwein et al., 2009). A precipitação pluvial, a temperatura e o balanço hídrico do período de desenvolvimento experimental estão apresentados na Figura 1.

Utilizou-se o delineamento de blocos ao acaso, sendo os tratamentos distribuídos em um fatorial 7 × 3 × 2 (resíduos culturais de inverno x manejo nitrogenado, no inverno x inoculação de sementes, no verão), com três repetições. As parcelas experimentais mediram $2 \mathrm{x}$ 4,5 metros $\left(9 \mathrm{~m}^{2}\right)$. As culturas utilizadas no inverno foram: trigo (Triticum aestivum L.), cevada (Hordeum vulgare sp.) e aveia preta (Avena strigosa Schreb). Foram utilizados os cultivares de trigo Fundacep Horizonte, Quartzo (OR/Biotrigo), Mirante (OR/Biotrigo), de ciclos médio e o cultivar Campo Real, de ciclo precoce; dois cultivares de cevada, BRS Cauê e a MN 743, de ciclo médio e precoce, respectivamente, e um cultivar de aveia preta (Moreninha). A escolha de números de 
cultivares diferentes para as culturas de cobertura foi realizada em função da variação na susceptibilidade a doenças apresentadas entre eles, bem como na duração de seu ciclo.

A semeadura das culturas de cobertura foi realizada com semeadora para plantio direto de cereais de inverno, no dia primeiro de junho de 2012. Para todas as culturas e cultivares, foi utilizado o espaçamento de 0,20 m entre fileiras, buscando-se a profundidade de $0,04 \mathrm{~m}$ e a densidade de 350 sementes $\mathrm{m}^{-2}$ (Embrapa, 2012). As culturas de inverno não receberam inoculação, sendo a adubação de base realizada segundo análise de solo e indicações para cada cultura. A adubação de cobertura (nitrogenada) foi realizada nas seguintes proporções: sem aplicação; 88,59 e 177,18 kg de $\mathrm{N} \mathrm{ha}^{-1}$ (SBCS-CQFS, 2004). Demais manejos, como controle de pragas, doenças e plantas daninhas foram realizados conforme a necessidade e indicações técnicas para as culturas (Embrapa, 2012).

A semeadura do milho foi realizada no dia 15 de novembro de 2012, em sistema plantio direto, sobre os resí-

Precipitação,Temperatura Média Decendial e

Temperatura-base da Cultura

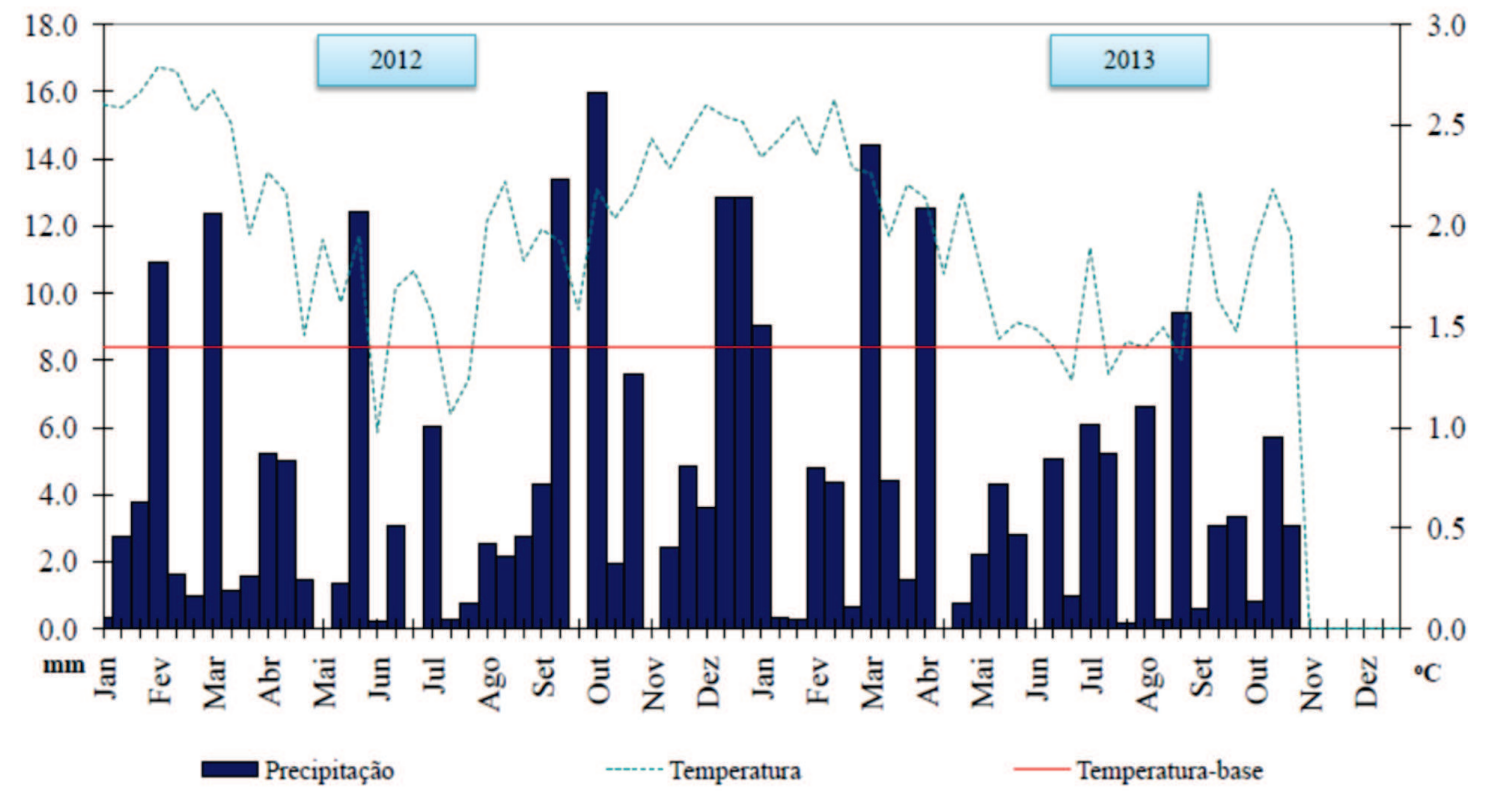

Extrato do Balanço Hidrico

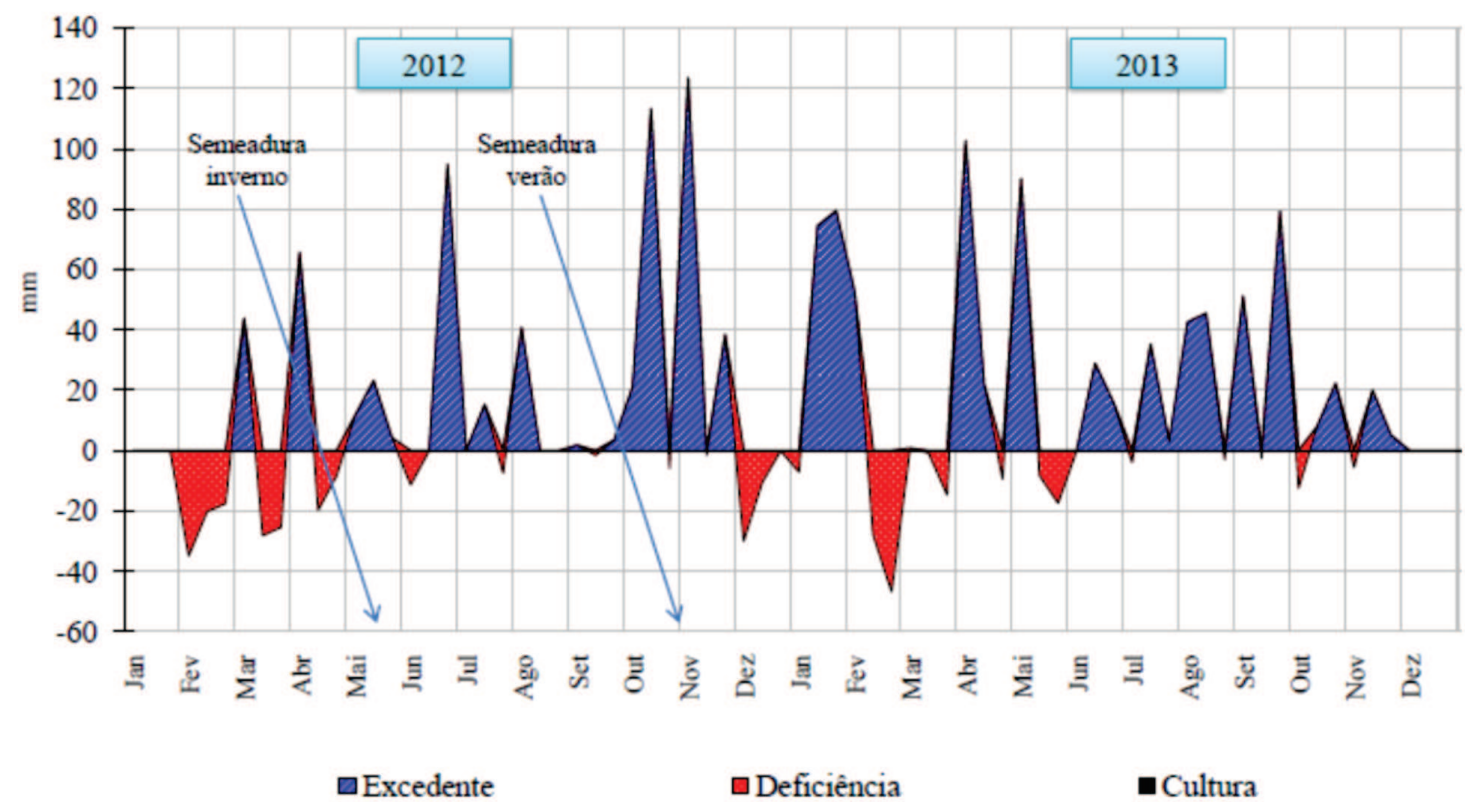

Figura 1: Precipitação pluvial, temperatura média decendial e balanço hídrico do período de desenvolvimento experimental. Santa Maria, RS, 2012. 
duos culturais de inverno, sendo utilizado o híbrido $\mathrm{P} 1630 \mathrm{H}$ (Pioneer Sementes). As parcelas com milho seguiram a mesma configuração utilizada para as culturas de inverno, sendo estas subdivididas em duas fileiras com sementes inoculadas e duas fileiras não inoculadas com Azospirillum brasilense, espaçadas de $0,5 \mathrm{~m}$. A adubação de base foi realizada segundo análise de solo e indicações para a cultura, porém, sem adubação de cobertura (nitrogenada).

Ao atingir o ponto de silagem (2/3 do grão leitoso), foi realizada a colheita de uma das duas fileiras de cada subparcela. O corte das plantas foi realizado a $0,90 \mathrm{~m}$ do solo, em função da baixa umidade dos colmos e folhas. Em seguida, as plantas foram trituradas em partículas de aproximadamente dois centímetros para a confecção da silagem.

Para o processo de ensilagem foram utilizados microssilos de saco plástico de $0,41 \mathrm{~m}$ de largura, 0,65 m de altura e 180 micras de espessura. Esses silos foram preenchidos com $500 \mathrm{~g}$ de areia para retenção dos efluentes provenientes da silagem. Em cada microssilo, devidamente identificado, foram colocados três quilogramas do material triturado, sendo este compactado com uma haste de madeira, a fim de reduzir a presença de ar para uma fermentação anaeróbica adequada. A abertura dos sacos foi vedada com fita adesiva e, o produto ensilado, armazenado por 41 dias. Após esse tempo, foram abertos os microssilos e retiradas as amostras para as análises qualitativas do produto ensilado.

As amostras foram colocadas em estufa com circulação de forçada ar, a $55^{\circ} \mathrm{C}$, até massa constante, obtendose assim a massa seca (MS) da silagem. Posteriormente, foram trituradas em moinho tipo faca, com peneira de 1 mm e submetidas à análise. Em função de resposta observada nos componentes da produtividade, os dados qualitativos do produto ensilado foram analisados como um fatorial $2 \times 3 \times 2$, selecionando-se os tratamentos com as doses zero e $177,18 \mathrm{~kg}$ de $\mathrm{N} \mathrm{ha}^{-1}$, cultivados sobre os resíduos dos cultivares do trigo Fundacep Horizonte, da cevada BRS Cauê e da aveia preta, com e sem inoculação de sementes. Para a determinação da proteína bruta, foi adotada metodologia proposta por Tedesco et al. (1995), com o teor de proteína bruta mensurado a partir do teor de nitrogênio presente na amostra analisada. A análise foi realizada pelo método de Kjeldahl, pelo qual a percentagem de nitrogênio obtida é multiplicada por 6,25 e, então, expressa como Proteína Bruta (PB). Para isto, considerouse que todas as proteínas do tecido vegetal contêm $16 \%$ de nitrogênio, todo ele na forma proteica. Os teores de fibra em detergente neutro foram obtidos segundo metodologia descrita por Van Soest et al. (1991) e o resíduo mineral, ou cinza bruta, com metodologia proposta por Silva \& Queiroz (2006).
Anteriormente à colheita, foram avaliadas as variáveis: número de espigas por hectare, por contagem do número espigas por metro linear e o seu valor extrapolado para hectare; número de grãos por espiga, pela multiplicação do número de fileiras pelo número de grãos por fileira; massa de cem sementes, segundo metodologia proposta por Brasil (2009) e produtividade de grãos, a partir da colheita das espigas de uma área de $4,05 \mathrm{~m}^{2}$, sendo a produção final de grãos corrigida para $13 \%$ de umidade e o valor extrapolado para quilogramas hectare ${ }^{-1}$.

Os dados foram submetidos à análise de variância, sendo ajustadas equações de regressão para o efeito das doses de $\mathrm{N}$ e, as médias, comparadas pelo teste de Tukey, a 5\% de probabilidade de erro. A análise estatística foi realizada com os programas estatísticos SOC - NTIA (Embrapa,1997) e Sisvar ${ }^{\circledast}$ (Ferreira, 2008).

\section{RESULTADOS E DISCUSSÃO}

O número de espigas ha-1 do milho cultivado sobre o resíduo cultural da cevada do cultivar BRS Cauê apresentou comportamento distinto daquele das demais culturas de cobertura (Figura 2A). Houve redução linear do número de espigas, com o aumento da dose de $\mathrm{N}$ aplicada na cultura da cevada. Essa redução pode ter ocorrido em função da maior incidência do fungo Gibberella zeae (Schw.). A susceptibilidade desse cultivar de cevada à giberela, mesmo que imperceptível no inverno, pode ter correlação positiva com a incidência do fungo no milho cultivado em sucessão. As podridões do colmo e da espiga ocorreram com maior incidência no milho cultivado em plantio direto sobre esse resíduo cultural (Reiset al., 2004). Além disso, o aporte de nitrogênio provoca a formação de tecidos jovens e suculentos, favorecendo a ocorrência da doença (Agrios, 1997).

Quanto ao número de grãos espiga ${ }^{-1}$ (Figura $2 \mathrm{~B}$ ), observou-se comportamento quadrático da curva de resposta do milho, em função das doses de $\mathrm{N}$, quando cultivado sobre os resíduos culturais do trigo (cultivar Fundacep Horizonte) e da cevada (BRS Cauê). Sobre esses resíduos, o ponto de máxima da curva de resposta ficou próximo à da metade da dose de $\mathrm{N}$. Isso indica que cultivares de uma mesma espécie respondem de maneira distinta à fertilização mineral, o que pode resultar em redução da recomendação de $\mathrm{N}$ para uma mesma resposta. No milho cultivado sobre os demais resíduos, não se observou interação quanto ao número de grãos por espiga com relação às doses de $\mathrm{N}$.

O número de grãos por espiga é influenciado pela disponibilidade hídrica durante o enchimento dos grãos (Amado et al., 2009). Dessa forma, as condições pluviométricas nessa fase (Figura 1) podem ter alterado a marcha de translocação de solutos e o enchimento dos grãos. Além 

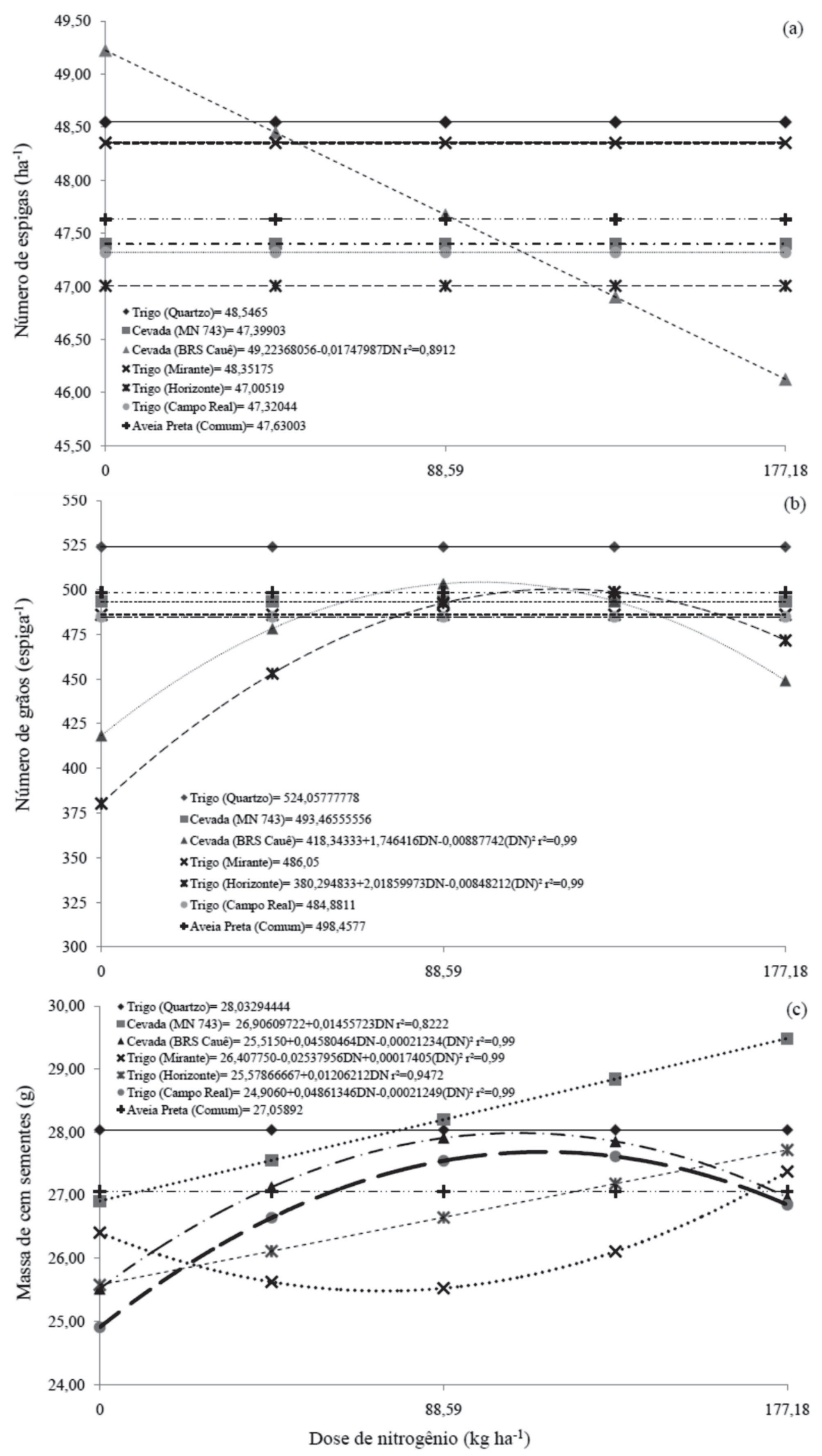

Figura 2: Número de espigas do milho (NE x 1000) cultivado sobre diferentes resíduos culturais de inverno e com diferentes doses de nitrogênio (A), número de grãos por espiga-do milho em função de resíduos culturais de inverno e doses de nitrogênio (B) e massa de cem sementes do milho em função de resíduos culturais de inverno e doses de nitrogênio (C). 
de a liberação de nutrientes ser controlada por diversos atributos intrínsecos aos resíduos (Aita et al., 2006), menores volumes de palhada produzidos pelo trigo (cultivar Fundacep Horizonte) e pela cevada (BRS Cauê) podem ter alterado o fluxo evaporativo e o tempo de permanência da umidade do solo (Machado et al., 2008; Leite et al., 2010).

A massa de cem sementes de milho, semelhantemente ao observado para o número de espigas $\mathrm{ha}^{-1} \mathrm{e}$ o número de grãos por espiga foram alterados em função do resíduo cultural e da dose de $\mathrm{N}$ utilizada (Figura 2C). Ambos os resíduos culturais do trigo (cultivar Fundacep Horizonte) e da cevada (cultivar MN 743) apresentaram incremento linear da massa de cem sementes de milho em função do aumento da dose de N. Os resíduos culturais do trigo (cultivar Quartzo) e da aveia preta não influenciaram a massa de cem sementes em nenhuma das doses testadas.

A diferença entre resíduos culturais pode estar associada à taxa com que ocorreu liberação de nutrientes e também à diferença na quantidade de resíduo produzido (Aita et al., 2006; Boer et al., 2007; Pariz et al., 2011; Teixeira et al., 2011). Assim, a taxa de liberação do nitrogênio dos resíduos culturais pode ter afetado, dentre outros processos, a magnitude das perdas de $\mathrm{N}$, alterando o potencial das coberturas de solo em atuarem como fontes de $\mathrm{N}$ para o milho (Aita et al., 2006; Crusciol et al., 2008; Kaneko et al., 2015). Culturas e cultivares apresentam marchas diferentes de decomposição, que alteram a disponibilidade de nutrientes e a época em que estes são disponibilizados para a cultura subsequente (Lázaro et al., 2013).

Com relação à produtividade de grãos, os resíduos culturais e as doses de nitrogênio não surtiram efeito sobre os resultados. Para as condições deste estudo, a produtividade foi responsiva somente à inoculação das sementes. Quando as sementes foram inoculadas, obteve-se a produtividade de grãos de $5,26 \mathrm{Mg} \mathrm{ha}^{-1}$, ao passo que, na ausência da bactéria, esse valor ficou em 4,54 $\mathrm{Mg} \mathrm{ha}^{-1}$.

Os efeitos da $A$. brasilense no desenvolvimento e na produtividade do milho têm sido atribuídos não somente ao papel de auxiliar na fixação biológica do nitrogênio (Cassán \& Salamone, 2008; Müller et al., 2016), mas, também ao fato de a bactéria modificar a morfologia do sistema radicular da cultura, aumentando não apenas o número de radicelas, mas, também, o diâmetro das raízes laterais e adventícias (Bashan et al., 2006; Cassán \& Salamone, 2008; Morais et al., 2015). Parte, ou, talvez, muitos desses efeitos nas plantas, podem ser atribuídos à produção, pela bactéria, de substâncias promotoras decrescimento, entre elas: auxinas, giberilinas e citocininas (Bashan et al., 2006) e não somente à fixação biológica de nitrogênio.

Quanto à qualidade bromatológica do produto ensilado, não foi observada diferença $(\mathrm{p}<0,05)$ para a variável cinza bruta (CB, \%), ao passo que as demais variáveis foram influenciadas pela aplicação dos tratamentos. Ao se considerarem os efeitos das doses de nitrogênio sobre a produção de massa seca, observam-se respostas do milho cultivado após as culturas da cevada e aveia preta semelhantes à da cultura do trigo (Tabela 1). A aplicação do fertilizante mineral incrementou em pelo menos 2,13 e 2,18 $\mathrm{Mg} \mathrm{ha}^{-1}$ os teores de massa seca do milho silagem cultivado, respectivamente, após a cultura da cevada e da aveia preta. Este incremento contribui para a conservação do material ensilado, inibindo o desenvolvimento de micro-organismos desfavoráveis e também possibilitando o aumento da concentração de nutrientes e o seu consumo pelos animais (Pizarro, 1978; Costa et al., 2013).

Com a utilização do inoculante não foram observadas estas mesmas respostas, o que pode estar associado a dois mecanismos. O primeiro está relacionado com a capacidade da bactéria de fixar nitrogênio atmosférico (Dobbelaere et al., 2003), fornecendo parcialmente a quantidade do nutriente exigido pelas plantas de milho. O segundo mecanismo diz respeito à produção de hormônios vegetais, como: giberelinas, auxinas e citocininas que podem ter atuado na morfologia radicular e na fisiologia das plantas, aumentando a eficiência de absorção e de utilização de água e nutrientes (Okon \& Vanderleyden, 1997; Perin et al., 2003).

As diferenças entre as relações $\mathrm{C} / \mathrm{N}$, lignina/ $\mathrm{N}$ e lignina + polifenóis/N dos diversos resíduos (Boer et al., 2007; Pariz et al., 2011; Teixeira et al., 2011) podem justificar a produção de aproximadamente $1 \mathrm{Mg} \mathrm{ha}^{-1}$ a menos de massa seca do milho silagem, cultivado após a cultura da aveia preta, na ausência de fertilização mineral. Aos 35 dias após o manejo, mais de $45 \%$ do $\mathrm{N}$ presente no resíduo pode já ter sido liberado da palha para o solo (Crusciol et al., 2008). Desta forma, a taxa de liberação do nitrogênio dos resíduos culturais pode ter afetado, entre outros processos, a magnitude das perdas de $\mathrm{N}$, diminuindo o potencial dos resíduos para atuarem como fontes de $\mathrm{N}$ para o milho (Aita et al., 2006; Crusciol et al., 2008; Kaneko et al., 2015).

A inoculação não apresentou influência sobre o teor de proteína da silagem. O milho cultivado após as culturas da cevada apresenta teor de PB maior, quando utilizada adubação mineral (Tabela 2). Como constituinte fundamental de aminoácidos, o nitrogênio é essencial na composição das moléculas de proteína (Malavolta et al., 1997). Quanto mais elevada for a quantidade de N mineral disponível, no solo, por ocasião do cultivo, maior o teor de proteína presente no tecido vegetal (Malavolta et al., 1997; Oliveira et al., 2013).

Com relação ao fator cultura, tanto na presença da fertilização mineral como na sua ausência, o milho cultivado após a cultura da cevada apresentou os valores mais 
Tabela 1: Teor de massa seca de milho silagem em função da cultura de inverno, doses de nitrogênio e inoculação de sementes.

\begin{tabular}{lcccc}
\hline & & \multicolumn{3}{c}{ Cultura } \\
\cline { 3 - 5 } DN & INO & Cevada & Trigo & Aveia Preta \\
\cline { 3 - 4 } & & & Mg ha $^{-1}$ & \\
\hline 0 & sem & b 15,38 a A & a 15,93 a A & b 13,92 b B \\
0 & com & a 15,98 a A & a 15,13 a B & a 14,94 a B \\
177,18 & sem & a 17,51 a A & a 15,11 a C & a 16,08 a B \\
177,18 & com & a 16,45 a A & a 14,94 a B & a 14,93 a B \\
\hline
\end{tabular}

"Médias com letras diferentes são diferentes entre si pelo teste de Tukey a 5\% de probabilidade de erro. Letras minúsculas e em negrito, na coluna, representam o comportamento das doses de nitrogênio dentro dos fatores inoculação e cultura. Letras minúsculas, na coluna e após o valor das médias, representam o comportamento da inoculação dentro dos fatores dose de nitrogênio e cultura. Letras maiúsculas, na linha, representam o comportamento da cultura dentro dos fatores inoculação e dose de nitrogênio.

Tabela 2: Teor de proteína bruta da silagem de milho, em função da cultura de inverno e das doses de nitrogênio.

\begin{tabular}{|c|c|c|c|}
\hline Dose de nitrogênio & \multicolumn{3}{|c|}{ Cultura } \\
\hline \multirow{2}{*}{$\mathrm{kg} \mathrm{ha}^{-1}$} & Cevada & Trigo & Aveia Preta \\
\hline & \multicolumn{3}{|c|}{ Proteína Bruta (\%) } \\
\hline 0 & $7,26 \mathrm{~b} \mathrm{~A}$ & $6,51 \mathrm{a} \mathrm{AB}$ & 5,79 b B \\
\hline 177,18 & 8,94 a A & 6,87 a B & 6,33 a $\mathrm{B}$ \\
\hline
\end{tabular}

"Médias seguidas por letras diferentes são diferentes entre si pelo teste de Tukey a 5\% de probabilidade de erro. Letras maiúsculas na linha representam o comportamento das culturas dentro do fator doses de nitrogênio. Letras minúsculas na coluna representam o comportamento das doses de nitrogênio dentro do fator cultura.

elevados de proteína bruta. Esse resultado pode estar associado à maior produção de massa seca que a cultura da cevada apresenta, em comparação com as demais (Santos \& Roman, 2001; Gazola \& Cavariani, 2011). Assim, a palhada remanescente protege a superfície do solo, garantindo menor variação da temperatura e maior umidade, além de disponibilizar nutrientes por um período de tempo maior durante o processo de decomposição (Torres et al., 2008; Costa et al., 2015). Como observado por Costa et al. (2015), a decomposição da palha acompanha a produtividade de massa seca total. Quanto mais palha produzida $\left(\mathrm{kg} \mathrm{ha}^{-1}\right)$, maior é a quantidade de nutrientes que poderão ser disponibilizados para as culturas semeadas em sucessão.

Quanto aos teores de fibra em detergente neutro (FDN), a silagem do milho cultivado após a cultura da cevada apresentou valores inferiores com relação ao que sucedeu às culturas do trigo (Tabela 3). Quanto menor for o teor de FDN, maior é a possibilidade de ingestão de MS (Visoná-Oliveira et al., 2015).

Tabela 3: Teor de fibra em detergente neutro da silagem de milho em função da cultura de inverno.

\begin{tabular}{lc}
\hline Cultura & Fibra em detergente neutro (\%) \\
\hline Cevada & $45,82 \mathrm{~b}$ \\
Trigo & $50,64 \mathrm{a}$ \\
Aveia Preta & $48,43 \mathrm{ab}$ \\
\hline
\end{tabular}

"Médias seguidas por letras diferentes são diferentes entre si pelo teste de Tukey a $5 \%$ de probabilidade de erro.
Como o nitrogênio exerce papel fundamental, tanto na produção de milho grão quanto na de milho de silagem, diferentes quantidades de $\mathrm{N}$ disponíveis para a cultura podem influenciar diretamente os componentes da planta (Neumann et al., 2005). Mais nitrogênio disponível resulta em plantas de milho com maior rendimento de grãos na massa ensilada (Von Pinho, 2007). Assim, menores são as percentagens de FDN e melhor a qualidade do alimento, uma vez que uma silagem rica em grãos apresenta maiores concentrações de amido e proteína bruta em relação à de fibras (Melo et al., 1999; Visoná-Oliveira et al., 2015).

\section{CONCLUSÕES}

A cobertura do solo com a cultura da cevada (cultivar BRS Cauê), no inverno, melhora a qualidade bromatológica da silagem de milho.

A inoculação com A. brasilense incrementa a produtividade de grãos, porém, não influencia no teor de proteína da silagem do milho.

\section{REFERÊNCIAS}

Agrios GN (1997) Plant pathology. 4 ${ }^{\mathrm{a}}$ ed. San Diego, Academic Press. 635p.

Aita C, Chiapinotto IC, Giacomini SJ, Hübner AP \& Marques MG (2006) Decomposição de palha de aveia preta e dejetos de suínos em solo sob plantio direto. Revista Brasileira de Ciência do Solo, 30:149-161.

Albuquerque AW, Santos JR, Moura Filho G \& Reis LS (2013) Plantas de cobertura e adubação nitrogenada na produção de milho em sistema de plantio direto. Revista Brasileira de Engenharia Agrícola e Ambiental, 17:721-726. 
Amado TJC, PesLZ, Lemainski CL \& Schenato RB (2009) Atributos químicos e físicos de Latossolos e sua relação com os rendimentos de milho e feijão irrigados. Revista Brasileira de Ciência do Solo, 33:831-843.

Bartchechen A, Fiori CCL, Watanabe SH \& Guarido RC (2010) Efeito da inoculação de Azospirillum brasiliense na produtividade da cultura do milho (Zea mays L.). Campo Digital, 5:56-9.

Bashan Y, Bustillos JJ, Leyva LA, Hernandez JP \&Bacilio M (2006) Increase in auxiliary photoprotective photosynthetic pigments in wheat seedlings induced by Azospirillum brasilense. Biologyand Fertility of Soils, 42:279-285.

Boer CA, Assis RL, Silva GP, Braz AJBP, Barroso ALL, Cargnelutti Filho A \& Pires FR (2007) Ciclagem de nutrientes por plantas de cobertura na entressafra em um solo de cerrado. Pesquisa Agropecuária Brasileira, 42:1269-1276.

Brasil (2009) Regras para análise de sementes. Brasília, MAPA/ ACS. 395p.

Cassán FD \& Salamone G (2008) Azospirillumsp.: cell physiology, plant interactions and agronomic research in Argentina. Buenos Aires, Asociación Argentina de Microbiologia. 266p.

Costa NR, Andreotti M, Ulian NA, Costa BS, Pariz CM \& Teixeira Filho MCM (2015) Acúmulo de nutrientes e tempo de decomposição da palhada de espécies forrageiras em função de épocas de semeadura. Bioscience Journal, 31:818-829.

Costa DA, Domingues FN, Astholpi MZ, Mota DA, Oaigen RP, Calonego J \&Miranda AS (2013) Influência do arranjo de plantas sobre a composição bromatológica da silagem de milho. Veterinária em Foco, 10:169-177.

Crusciol CAC, Moro E, Lima EV \& Andreotti M (2008) Taxas de decomposição e de liberação de macronutrientes da palhada de aveia preta em plantio direto. Bragantia, 67:481-489.

SBCS-CQFS - Sociedade Brasileira de Ciência do Solo. Comissão de Química eFertilidade do Solo (2004) Manual de adubação e calagem para os estados do Rio Grande do Sul e Santa Catarina. $10^{\mathrm{a}}$ ed. Porto Alegre, Sociedade Brasileira de Ciência do Solo. 400p.

Dobbelaere S, Vanderleyden J \& Okon Y (2003) Plant growthpromoting effects of Diazotrophs in the Rhizosphere. Critical Reviews in Plant Sciences, 22:107-149.

Embrapa - Empresa Brasileira de Pesquisa Agropecuária (2012) Informações Técnicas para trigo e triticale. Brasília, Embrapa. 204p.

Embrapa - Empresa Brasileira de Pesquisa Agropecuária (2013) Sistema brasileiro de classificação de solos. $3^{a}$ ed. Brasília, Embrapa. 353p.

Embrapa - Empresa Brasileira de Pesquisa Agropecuária (1997) Ambiente de software NTIA. Campinas, Centro Nacional de Pesquisa Tecnológica em Informática para a Agricultura. 258p.

Ferreira DF (2008) Sisvar: um programa para análises estatísticas e ensino de estatística. Revista Symposium, 6:36-41.

Gazola E \& Cavariani G (2011) Desempenho de cultivares transgênicas de soja em sucessão a culturas de inverno em semeadura direta. Bioscience Journal, 27:748-763.

Godoy JCS, Watanabe SH, Fiori CCL \& Guarido RC (2011) Produtividade de milho em resposta a doses de nitrogênio com e sem inoculação das sementes com Azospirillum brasilense. Campo Digital, 6:26-30.

Heldwein AB, Buriol AG \& Streck NA (2009) O clima de Santa Maria. Ciência \& Ambiente, 38:43-58.

Kappes C, Arf O, Arf MV, Ferreira JP, Dal Bem EA, Portugal JR \&Vilela RG (2013) Inoculação de sementes com bactéria diazotrófica e aplicação de nitrogênio em cobertura e foliar em milho. Semina: Ciências Agrárias, 34:527-53.
Kaneko FH, Arf O, Sabundjian MT, Ferreira JP, Gitti DC, Leal AJF \& Nascimento V (2015) Fontes e modos de aplicação de nitrogênio na cultura do milho em sistema plantio direto. Brazilian Journal of Biosystems Engineering, 9:191-196.

Hungria M (2011) Inoculação com Azospirillum brasilense: inovação em rendimento a baixo custo. Londrina, Embrapa Soja, 37p. (Documentos, 325).

Lázaro RL, Costa ACT, Silva KF, Sarto MVM \& Duarte Júnior JB (2013) Produtividade de milho cultivado em sucessão à adubação verde. Pesquisa Agropecuária Tropical, 43:10-17.

Leite LFC, Freitas RCA, Sagrilo E \& Galvão SRS (2010) Decomposição e liberação de nutrientes de resíduos vegetais depositados sobre Latossolo Amarelo no Cerrado Maranhense. Revista Ciência Agronômica, 41:29-35.

Machado JL, Tormena CA, Fidalski J \& Scapin CA (2008) Interrelações entre as propriedades físicas e os coeficientes da curva de retenção de água de um Latossolo sob diferentes sistemas de uso. Revista Brasileira de Ciência do Solo, 32:495-502.

Malavolta E, Vitti GC \& Oliveira AS (1997) Avaliação do estado nutricional das plantas: princípios e aplicações. $2^{\mathrm{a}}$ ed. Piracicaba, Associação Brasileira para Pesquisa da Potassa e do Fosfato. $319 \mathrm{p}$.

Martin TN, Pavinato OS, Silva MR, Ortiz S \& Bertonceli P (2011) Fluxo de nutrientes em ecossistemas de produção de forragens conservadas. In: IV Simpósio sobre produção e utilização de forragens conservadas, Maringá. Anais, UEM. p.173-219.

Mumbach GL, Kotowski FJA, Schneider MS, Mallmann ÉB, Bonfada VO, Portela ÉB \& Bonfada DRK (2017) Resposta da inoculação com Azospirillum brasilense nas culturas de trigo e de milho safrinha. Revista Scientia Agraria, 18:97-103.

Melo WMC, Von Pinho RG, Von Pinho EVR, Carvalho MLM \& Fonseca AH (1999) Parcelamento da adubação nitrogenada sobre o desempenho de cultivares de milho para produção de silagem. Revista Ciência e Agrotecnologia, 23:608-616.

Milléo MVR \& Cristófoli I (2016) Avaliação da eficiência agronômica da inoculação de Azospirillum sp. na cultura do milho. Revista Scientia Agraria, 17:14- 23.

Morais TP, Brito CH, Ferreira AS \& Luz JMQ (2015) Aspectos morfofisiológicos de plantas de milho e bioquímico do solo em resposta à adubação nitrogenada e à inoculação com Azospirillum brasilense. Revista Ceres, 62:507-509.

Morais TP, Brito CH, Brandão AM \& Rezende WS (2016) Inoculation of maize with Azospirillum brasilense in the seed furrow. Revista Ciência Agronômica, 47:290-298.

Müller TM, SadiniIE, Rodrigues JD, Novakowiski JH, Basi S \&Kaminski TH (2016) Combination of inoculation methods of Azospirilum brasilense with broadcasting of nitrogen fertilizer increases corn yield. Ciência Rural, 46:210-215.

Neumann M, Sadini IE, Lustosa SBC, Ost PR, Romano MA, Falbo MK \&Pansera ER (2005) Rendimentos e componentes de produção da planta de milho (Zea mays L.) para silagem, em função de níveis de adubação nitrogenada em cobertura. Revista Brasileira de Milho e Sorgo, 4:418-427.

Okon Y \&Vanderleyden J (1997) Root-associated Azospirillum species can stimulate plants. Applied and Environmental Microbiology, 63:366-370.

Oliveira DF, Coelho AR, Burgardt VCF, Hashimoto EH, Lunkes AM, Marchi JF \& Tonial IB (2013) Alternativas para um produto cárneo mais saudável: uma revisão. Brasilian Journal of Food Technology, 16:163-174. 
Pariz CM, Andreotti M, Buzetti S, Bergamaschine AF, Ulian NA, Furlan LC, Meirelles PRL \& Cavasano FA (2011) Straw decomposition of nitrogen-fertilized grasses intercropped with irrigated maize in an integrated crop livestock system. Revista Brasileira de Ciência do Solo, 35:2029-2037.

Peel MC, Finlayson BL \& Mcmahon TA (2007) Updated world map of the Koppen-Geiger climate classification. Hydrology Earth System Science, 11:1633-1644.

Perin L, Silva MF, Ferreira JS, Canuto EL, Medeiros AFA, Olivares FL \& Reis VM (2003) Avaliação da capacidade de estabelecimento endofítico de estirpes de Azospirillume Herbaspirillum em milho e arroz. Revista Ciência Agronômica, Seropédica, $37: 47-53$

Pizarro EA (1978) Conservação de forragens. Informe Agropecuário, 4:20-28.

Pires JLF, Vargas L \& Cunha GR (2011) Trigo no Brasil: bases para produção competitiva e sustentável. Passo Fundo, Embrapa Trigo. 488 p.

Reis EM, Casa RT \& Bresolin ACR (2004) Manual de diagnose e controle de doenças do milho. Lages, Graphel. 141p.

Salomone G \& Döbereiner J (1996) Maize genotypes effects on the response to Azospirillum inoculation. Biology Fertilizer Soils, 21:193-196.

Sangoi L, Silva L, Mota M, Panison F, Schmitt A, Souza N, Giordani W \& Schenatto D (2015) Desempenho agronômico do milho em razão do tratamento de sementes com Azospirillum sp. e da aplicação de doses de nitrogênio mineral. Revista Brasileira de Ciência do Solo. 39:1141-1150.
Santos HP \& Roman ES (2001) Efeitos de culturas de inverno e rotações sobre a soja cultivada em sistema plantio direto. Pesquisa Agropecuária Gaúcha, 7:59-68.

Silva DJ \& Queiroz AC (2006) Análise de alimentos: métodos químicos e biológicos, $3^{\mathrm{a}}$ ed. Viçosa, UFV. 235p.

Taiz L \& Zeiger E (2013) Fisiologia Vegetal. 5a ed. Porto Alegre, Artmed. 918p.

Tedesco MJ, Gianello C, Bissani CA, Bohnen H \&Volkweiss SJ (1995) Análises de solo, plantas e outros materiais. $2^{\mathrm{a}}$ ed. Porto Alegre, UFRGS. 174p. (Boletim Técnico, 5).

Teixeira MB, Loss A, Pereira MG \& Pimentel C (2011) Decomposição e liberação de nutrientes da parte aérea de plantas de milheto e sorgo. Revista Brasileira de Ciência do Solo, 35:867876.

Torres JLR, Pereira MG \&Fabian AJ (2008) Produção de fitomassa por plantas de cobertura e mineralização de seus resíduos em plantio direto. Pesquisa Agropecuária Brasileira, 43:421-428.

Van Soest PJ, Robertson JB \& Lewis BA (1991) Methods for dietary fiber, neutral detergent fiber and non starch polysaccharides in relation to animal nutrition. Journal of Dairy Science, 74:3583-3597.

Visoná-Oliveira M, Ferreira IC, Macedo Junior GL, Sousa LF, Sousa JTL \& Santos RP (2015) Consumo e digestibilidade de nutrientes da torta de dendê na dieta de ovinos. Ciência Animal Brasileira, 16:179-192.

Von Pinho RG, Vasconcelos RC, Borges ID \& Resende AV (2007) Produtividade e qualidade da silagem de milho e sorgo em função da época de semeadura. Bragantia, 66:235-245. 